\title{
THE GENERIC DISTINCTION OF THE GOUGH ISLAND FLIGHTLESS GALLINULE
}

\author{
by \\ K. H. VOOUS \\ Zoological Museum, University of Amsterdam \\ Zoological Laboratory, Free University, Amsterdam
}

\section{INTRODUCTION}

The presence of five specimens of Gough Island Gallinules, Porphyriornis nesiotis comeri Allen, in the Zoological Gardens of Amsterdam originating from the remote Gough Island situated within the subantarctic confines of the South Atlantic Ocean, offered a favourable occasion for a study of these peculiar and rare birds. The Gough Island Gallinule is presently the only surviving representative of its species; the Tristan da Cunha form, $P$. nesiotis nesiotis (P. L. SCLATER), having been exterminated by man probably nearly a century ago. It belongs to a group of rails of which also the Moorhen or Common Gallinule, Gallinula chloropus, is a representative. From the latter species it differs among others by having greatly reduced powers of flight. One can wonder, however, about the degree of relationship between members of the genus Gallinula on the one hand and the Gough Island Gallinule on the other hand. In fact, the general appearance of the Gough Island Gallinule is that of a very stout, strongly legged Common Gallinule with a more skulking, less graceful gait. The birds in captivity in the Amsterdam Zoo were very pugnacious, a habit which has also been recorded by previous authors. When in pursuit of each other the birds frequently uttered a sharp, rattling call, which was also described by HoLdgate (1958) from birds observed in Gough Island and transliterated as a rapid "chack-chack". It seems that this call has not been recorded from any member of Gallinula chloropus. In spite of these differences RIPLEY (1954), in reviewing the "genera" Gallinula, Porphyriornis and Ionornis, has doubted the justification of the use of a separate genus name for the Flightless Gallinules from Tristan and Gough Island, which he would prefer to treat as members of the genus Gallinula. This question will again be considered here.

\section{ACKNOWLEDGMENTS}

I am much indebted to Dr. E. F. JACOBI, Director of the Zoological Gardens of Amsterdam, for presenting two dead specimens and one egg shell of the Gough Island Gallinule to the Zoological Museum and to place at my disposal some notes from the Zoo's daily journal.

Mr. P. Wedzinga, during a study which formed part of his doctoral work for biology at the Free University at Amsterdam, made a comparative study under my care of the skeleton of the Gough Island Gallinule and the Moorhen. I am thankful to be able to quote freely from his report.

\section{BREEDING IN THE ZOOLOGICAL GARDENS OF AMSTERDAM}

The Zoological Gardens of Amsterdam obtained by purchase from Mr. Отто GräвER (Brake, Germany) five adult specimens of Gough Island Gallinules which arrived on November 1st, 1956. One of these birds died on May 13th, 1957, another on September 3rd, 1959. The remains of the first (P) was presented to the Zoological Museum of Amsterdam and is preserved as a study-skin; those of the second ( $($ ) was made into a skeleton.

These birds have been kept in a single cage, often in company with some smaller herons. In the early days of May 1958 at least one pair laid eggs, all of which, however, proved to be infertile. One of these eggs has been presented to the Zoological Museum. The nest was made on the ground in a corner of the cage. Again, in 1959, a nesting attempt was made. Now, from March 30 onwards three birds were engaged in building a nest of the elongated leaves of a Bambusa at about six feet above the ground on top of an artificial nest in the fork of a small tree with a gently sloping trunk, which the bird could ascend 
without flying. The first egg was found on June 7 . On June 28 three eggs were present; on July 8 there were four eggs. On July 15 two young hatched, both of which remained in the nest and were fed and cared for by three adults. One of the chicks died the same day (July 15); its skin is in the Zoological Museum of Amsterdam. The other chick grew up successfully and is still living at present (early 1961). The remaining eggs were transfered into the incubator, but the embryos died before hatching.

Breeding in captivity of these rare birds has been first described by WiLson and Swales (1958) with birds caught during the Gough Island Scientific Survey (Holdgate, 1958) in 1956, at the Field Station for the Study of Animal Behaviour, Madingley,.Cambridge, England. The incubation period was recorded by these authors to be 21 days.

\section{ADULT PLUMAGE}

'The adult plumage closely resembles that of Gallinula chloropus. A fine colour plate of the Tristan race of Flightless Gallinule (nesiotis) can be found in the Proceedings of the Zoological Society, London, 1861, pl. XXX. The differences with the Gough Island race (comeri) are very slight if constant at all. But this question does not occupy us here.

In comparison with Gallinula chloropus the Gough Island Gallinule has the plumage somewhat darker, more deeply blackish grey; the feathers being somewhat longer and more hairy, particularly on the head, the neck and the mantle. The light grey-and-white cross barring on the central abdomen present in Gallinula chloropus is absent and the broad white streaks on the flank feathers of Gallinula chloropus are equally strongly reduced in Porphyriornis nesiotis. The wing is shorter and rounder, the proximal parts of the primaries softer and weaker and lack the rigidity for flight. The tip of the wing is formed by the 3rd (in some specimens $=2 \mathrm{nd}$ ) outermost primary, as against the 2nd in the Common Moorhen. The horny tubercle on the thumb is more apparent; in some specimens it is even forming a real small wing-spur. The bill is considerably thicker and the frontal shield is relatively large. The legs and toes are also thicker. The colour of the legs and feet differ from those of Gallinula chloropus. They are dull orange reddish, irregularly blotched and spotted all over with yellow or greenish yellow; the horn covered part of the lower tibiotarsus is mainly reddish, as in the Moorhen.

\section{JUVENILE PLUMAGE}

The juvenile plumage is dark umber brown all over, lacking the white on the chin, the abdomen, and the under tail coverts, which are characteristic of the juvenile plumage of Gallinula chloropus. Even the white flank stripes of the juvenile Moorhen are absent in the young Gough Island Gallinule. Legs and feet are light grey with a slight greenish tinge. The bill and the small horny frontal shield are black with a dull yellowish tip. By its. uniform dull coloration, its stout legs and thick bill the impression made by the young of the Gough Island Gallinule is quite different from that of the young Moorhen. The different juvenile plumage appears one of the strongest arguments in favour of the separation of the Gough Island Gallinule under the name Porphyriornis. However, the difference noticed may as well be considered to be the effect of the need of a protective coloration against avian predators in the low scrub of the bird's native island.

A similar description of the brown juvenile plumage has been given by Holdgate (1958) and WiLson \& Swales (1958).

\section{DOWNY CHICK}

The less than one day old downy chick corresponds with the description by RIPLEY (1954, p. 4) of a chick collected in Gough Island on 15 December 1952. It is black all over with a slight greenish gloss on the upper parts and has white downy spots on the sides of the head and neck. It closely resembles the chick of Gallinula chloropus, but the length of the down is slightly longer and the head seems slightly more covered with down. Legs and feet are black; bill horngrey with dark tip, base of upper mandible pale reddish.

\section{THE EGG}

One egg from the unsuccessful breeding attempt from 1958 resembles the egg of Gallinula chloropus in shape and coloration, but it is considerably larger. The ground colour is cream with scattered reddish brown spots and blotches, slightly coarser than generally found in Moorhen eggs and with a heavy concentration on the broad pole, where the brown coloration almost forms a small cap. The secondary spots are purplish. Measurements: $52.0 \times 34.1 \mathrm{~mm}$. The average of 50 eggs of Gallinula chloropus from the Netherlands is given by DE Vrues (in: EyKMan c.s., "De Nederlandsche Vogels", III, 1948, p. 1017) as $43.6 \times 30.6 \mathrm{~mm}$.

The egg perfectly agrees with the first description of the eggs of this species from Gough Island by Wilson \& Swales (1958). 

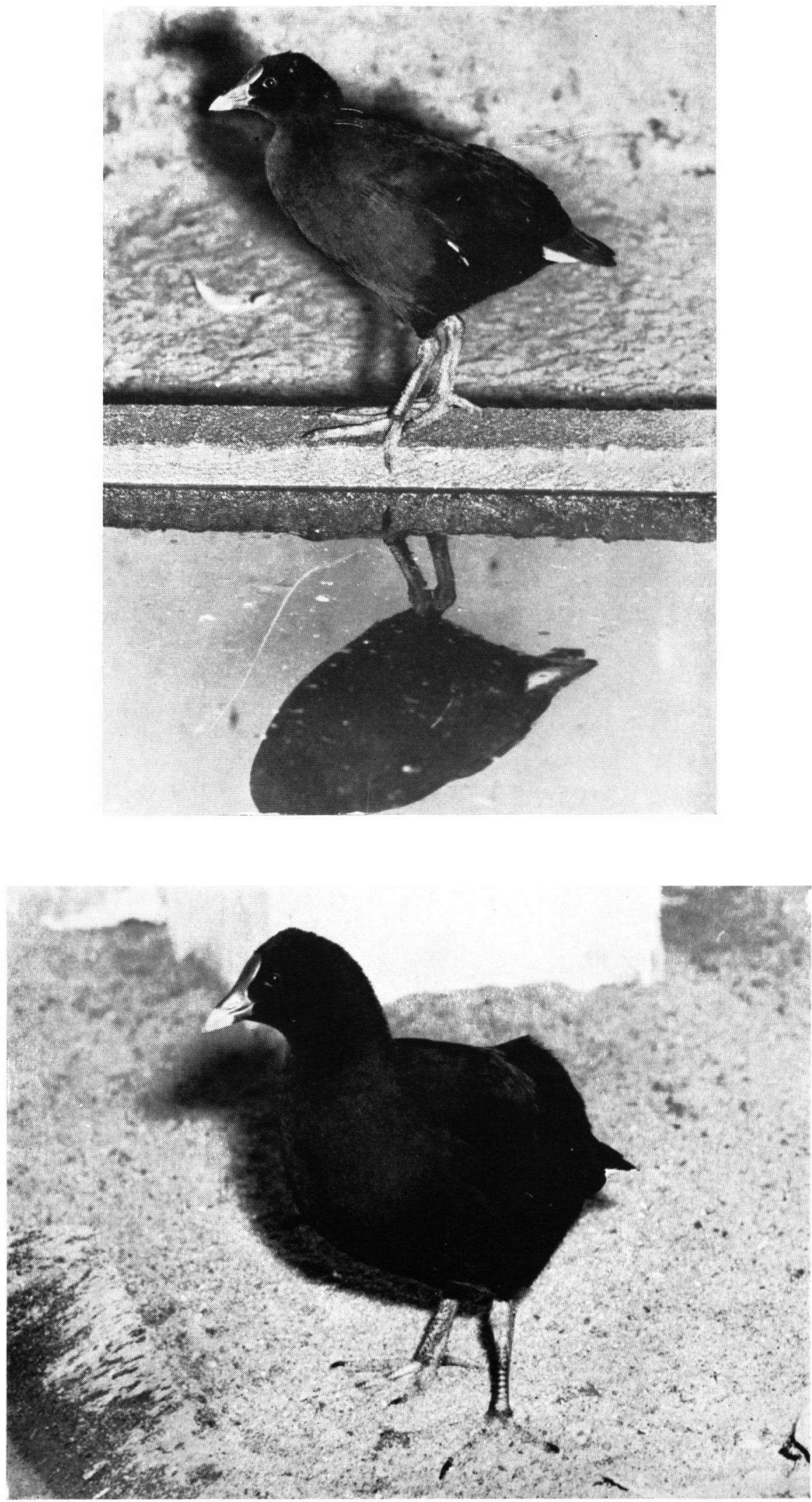

Porphyriornis nesiotis comeri Allen. 


\section{EXTERNAL MEASUREMENTS}

The following measurements (in $\mathrm{mm}$ ) are those of four specimens of Porphyriornis n. comeri:

a) Collection nr. 14490, female, Zoological Gardens of Amsterdam (13 May 1957).

b) Collection nrs. 14695-7, two males and one female, collected by Mr. N. Scheer on Gough Island on 26 February 1960 and sent as study-skins to the Zoological Museum of Amsterdam.

The measurements have been compared with the average measurements of 10 adult Gallinula c. chloropus from the Netherlands. The comparison clearly shows the presence in Porphyriornis nesiotis of a relatively shorter wing and a shorter middle toe.

\section{OSTEOLOGICAL MEASUREMENTS}

The following measurements (in $\mathrm{mm}$ ) have been taken from one female Porphyriornis nesiotis comeri (Zoological Gardens, 3 September 1959) and one female Gallinula chloropus chloropus from the Netherlands.

1. length of cranium length of pterygoid greatest length (height) of quadratum

2. length of sternum width of sternum ${ }^{1}$ ) length of crista sterni depth of crista sterni length of coracoid length/width of sternum length/depth of crista sterni length coracoid/depth crista sterni

Porp

3. length of humerus width shaft of humerus length of radius length of ulna length first finger +claw (right) $9.1+3.7$ length metacarpale II (right) $\mathbf{2 7 . 0}$ length second finger (right) 44.7 humerus/ulna ulna/2nd finger

\section{8}

49.7

length of synsacrum
width of synsacrum acetabulum pre-acetabular part of synsacrum 2)

post-acetabular part of synsacrum ${ }^{2}$ )

pre-acetabular/post-acetabular part of synsacrum

19.2
33.2
21.9
1.5

1) Measured between tips of processus lateralis anterior.

2) Measured from the antitrochanter.
5. length of femur width shaft of femur length of tibiotarsus length of tarsometatarsus length hallux +claw (right) length third (middle) toe + claw (right)

femur/tibiotarsus

tibiotarsus/third toe (without claw)

$\begin{array}{ll}55.0 & 52.0 \\ 4.6 & 4.3 \\ 81.4 & 84.2 \\ 47.0 & 50.0 \\ 18.3+10.6 & 24.3+10.0 \\ & \\ 49.0+15.2 & 54.2+14.4 \\ 0.7 & 0.6 \\ & \\ 1.7 & 1.6\end{array}$

\section{OSTEOLOGICAL REMARKS}

In all osteological characters, including the skull, the Gough Island Gallinule resembled the Moorhen, except for considerable proportional differences in the shoulder girdle and the fore limbs, and in the pelvic girdle and the hind limbs.

The shoulder girdle of the Gough Island Gallinule shows the characteristics of the reduction of the use of the wings: (1) smaller surface and shorter length of the breast bone, (2) considerably lower breast bone crest (23\% of the length of the sternum in Porphyriornis nesiotis, as against $32 \%$ in Gallinula chloropus), at the same time resulting in a sharper angle between the coracoid and the furcular bone. The number of ribs articulating with the breast bone was found to be 5 in the Gough Island Gallinule and 6 in the Moorhen.

As regards the proportions of the arm skeleton, the relative shortness of the ulna in Porphyriornis nesiotis is noteworthy. Wings with reduced powers of flight generally have a short ulna. Hence in Porphyriornis nesiotis we found the ulna to represent $77 \%$ of the length of the humerus as against in Gallinula chloropus $80 \%$. VERHEYEN (1957, p. 33) found in three specimens of Gallinula chloropus these proportions as follows: $83 \%, 83 \%, 84 \%$. In the table of measurements of skeleton parts of Rallidae VERHEYEN (1957, p. 32) lists as largest figures in this respect the members of the genera Porphyrio (humerus/ulna index 1.01-1.11 = ulna 90-99\% of humerus) and Porphyrula (humerus/ulna index $1.10=91 \%$ ). As smallest figures are mentioned those relating to Atlantisia rogersi, the perfectly flightless rail from Inaccessible Island in the Tristan da Cunha group (humerus/ulna index $1.43=70 \%)$. Therefore our figures are indicative of Porphyriornis nesiotis occupying a satisfactorily intermediate stage of development between the flying Moorhens of the genus Gallinula and the flightless stage of Atlantisia rogersi.

The proportions of the pelvic girdle of Porphyriornis nesiotis show the consequencies of a running and skulking life under plant cover and over the thick branches of the stunted Gough Island tree (Phylica 


\begin{tabular}{|c|c|c|c|c|c|c|}
\hline & \multicolumn{4}{|c|}{ Porphyriornis nesiotis comeri } & \multicolumn{2}{|c|}{ Gallinula chloropus chloropus } \\
\hline & $\begin{array}{c}\text { nr. } 14490 \\
\text { female }\end{array}$ & $\begin{array}{c}\text { nr. } 14696 \\
\text { female }\end{array}$ & $\begin{array}{l}\text { nr. } 14695 \\
\text { male }\end{array}$ & $\begin{array}{l}\text { nr. } 14697 \\
\text { male }\end{array}$ & $\begin{array}{l}\text { average of } \\
\text { ten males }\end{array}$ & $\begin{array}{l}\text { average of } \\
\text { ten females }\end{array}$ \\
\hline $\begin{array}{l}\text { Wing } \\
\text { Bill }^{1} \text { ) } \\
\text { Bill }^{2} \text { ) } \\
\text { Tarsus } \\
\text { Hallux }^{8} \text { ) } \\
\text { Middle toe }^{\text {) }} \\
\text { Wing/tarsus } \\
\text { Tarsus/middle toe }\end{array}$ & $\begin{array}{l}139.5+ \\
15.5 \\
40+ \\
50 \\
16 \\
50 \\
2.80 \\
1.00\end{array}$ & $\begin{array}{l}142 \\
14.5 \\
42.5 \\
50 \\
15.5 \\
50.5 \\
2.84 \\
0.99\end{array}$ & $\begin{array}{l}144.5 \\
16.5 \\
46.5 \\
52 \\
15 \\
54.5 \\
2.78 \\
0.95\end{array}$ & $\begin{array}{l}141.5 \\
16 \\
45 \\
52 \\
18 \\
54 \\
2.72 \\
0.96\end{array}$ & $\begin{array}{c}182.3 \\
15.0 \\
38.5 \\
52.0 \\
19.6 \\
59.1 \\
3.51 \\
0.88\end{array}$ & $\begin{array}{c}176.0 \\
14.6 \\
36.4 \\
49.4 \\
17.8 \\
56.6 \\
3.56 \\
0.87\end{array}$ \\
\hline
\end{tabular}

1) Measured from nostril.

2) Measured from posterior end of frontal shield.

3) Without claw.

arborea), rather than that of gracefully wading among a marsh vegetation at the water's edge as practicized by Gallinula chloropus. Hence in Porphyriornis nesiotis the synsacrum is relatively broad with a great acetabular width and a forward shift of the acetabulum, which can be numerically expressed by the relative large proportion of the post-acetabular part of the synsacrum. Thus, the implantation of the hind limb is nearer to the centre of gravity of the bird's body. In addition the synsacrum of Porphyriornis nesiotis is more arched and the pubes more directed downwards than in the Moorhen.

Leg musculature is stronger and more robust in the Gough Island Gallinule than in the Moorhen. The surface of origin of both adductors and abductors on the synsacrum is larger than in the Moorhen. The femur is longer, but all other parts of the hind limb are shorter, though stouter. The crista patellaris on the proximal end of the tibia is strikingly large: length $9.1 \mathrm{~mm}$, as campared with $7.9 \mathrm{~mm}$ in the Moorhen. In accordance with this difference of development the Musculus femoritibialis (one of the principal extensors of the lower limb) is much stronger in Porphyriornis nesiotis than in Gallinula chloropus and hence strongly promotes the smooth and stealthy walk by which the Gough Island Gallinule differs from the Moorhen. In general the whole of the hind limb in Porphyriornis nesiotis is stronger and shorter than in Gallinula chloropus.

\section{ZOOGEOGRAPHICAL CLASSIFICATION OF TRISTAN AND GOUGH ISLAND RAILS}

In the species of rails recorded from the Tristan da Cunha group and Gough Island the following tentative scala of oversea-colonists can be arranged.
1. Extremely rare vagrant from South America : one record from Tristan (Winterbottom, Ibis, 100, 1958, p. 285) : Fulica armillata.

2. More regularly occurring, but still rare vagrant from South America : more than 10 records from Tristan, mainly of birds in immature plumage (ELLIoTT, Ibis, 99, 1957, p. 579) : Porphyrula martinica : a strong flyer!

3. Slightly changed, presently sedentary offshoot of oversea-colonists of former South American Gallinules of the Gallinula chloropus group in Tristan da Cunha (extinct) and Gough Island (still flourishing : Holdgate, 1958) : Gallinula (sive Porphyriornis) nesiotis : flightless, wings moderately reduced in length.

4. Highly changed and specialized offshoot of an oversea-colonist of unknown origin, presently sedentary in Inaccessible Island, Tristan group : Atlantisia rogersi : fully flightless, wings greatly reduced in length.

This tentative scala of existing forms of a zoogeographical phenomenon of colonization gives support to the theory of accidental oversea-colonization, probably from a South American origin, broadly developed by RIPLEY (1954), but somewhat doubted by RAND (1956). In addition the process of the reduction of the power of flight and the anatomical consequences involved are clearly observable in the Gough Island Gallinule as modifications on the pattern of present Gallinula chloropus.

\section{GENERIC DISTINCTION}

Thus, in all respects the Gough Island Gallinule represents a stage of development which can be attributed to the effect of a skulking and flightless life on a small oceanic island, where terrestrial predators are 
absent and where, according to Martin Holdgate (1958) only the Antarctic Skuas (Stercorarius skua lönnbergi) form a threatening menace for which the birds have to keep under protective plant cover. It is a matter of opinion whether this stage of development which, as it seems, was clearly derived from a Gallinula stock, already has diverged sufficiently far for making the use of a separate genus name practicable. By formulating this I refrain from stating the question of whether a separate genus should be erected or not, since I do not believe in the "existence" of genera.

It is my point of view that the Flightless Gallinules from Tristan and Gough Island can best be treated under the name which most clearly demonstrates it as an insular semi-flightless species of the world-wide group of Moorhens summarized under the name Gallinula.

\section{REFERENCES}

Elliotr, H. F. I., 1957: A contribution to the ornithology of the Tristan da Cunha group. Ibis, 99: pp. 545-586.

Holdgate, M., 1958: Mountains in the sea. The story of the Gough Island Expedition. London (MacMillan \& Co).

RaND, A. L., 1955: The origin of the land birds of Tristan da Cunha. Fieldiana: Zoology, 37: pp. 139-163. Ripley, S. D., 1954: Birds from Gough Island. Postilla,
Yale Peabody Museum, 19: pp. 1-6.

Verheyen, R., 1957: Contribution au démembrement de l'ordo artificiel des Gruiformes (Peters 1934). I. - Les Ralliformes. Bull. Inst. Roy. Sc. nat. Belg., 23 (21): pp. $1-44$.

Wilson, E. A. \& M. K. Swales, 1958: Flightless Moorhens (Porphyriornis c. comeri) from Gough Island breed in captivity. Avicultural Magazine, 64: pp. 43-45. 